\title{
Photocatalytic Oxidative C-H Thiolation: Synthesis of Benzothiazoles and Sulfenylated Indoles
}

\author{
Andrew N. Dinh $\ddagger$ \\ Ashley D. Nguyen $\ddagger$ \\ Ernesto Millan Aceves \\ Samuel T. Albright \\ Mario R. Cedano \\ Diane K. Smith \\ Jeffrey L. Gustafson*
}

Department of Chemistry and Biochemistry, San Diego State University, 5500 Campanile Dr, San Diego, CA, 92182-1030, USA

jgustafson@sdsu.edu

$\ddagger$ Both authors contributed equally

Published as part of the Cluster for Organosulfur and Organoselenium Compounds in Catalysis

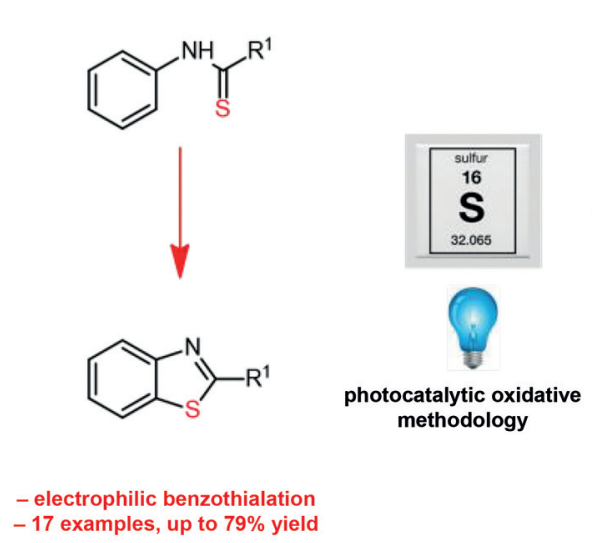<smiles>[R]c1cn([R])c2ccccc12</smiles><smiles>[R1]c1ccc(Sc2c([R])c3ccccc3n2[R])cc1</smiles>

- nucleophilic indole sulfenylation -10 examples, up to $68 \%$ yield

Received: 24.04.2019

Accepted after revision: 17.06 .2019

Published online: 27.06 .2019

DOI: 10.1055/s-0039-1690107; Art ID: st-2019-w0235-c

Abstract We report studies on the photocatalytic formation of $\mathrm{C}-\mathrm{S}$ bonds to form benzothiazoles via an intramolecular cyclization and sulfenylated indoles via an intermolecular reaction. Cyclic voltammetry (CV) and density functional theory studies suggest that benzothiazole formation proceeds via a mechanism that involves an electrophilic sulfur radical, while the indole sulfenylation likely proceeds via a nucleophilic sulfur radical adding into a radical cationic indole. These conditions were successfully extended to several thiobenzamides and indole substrates.

Key words photoredox catalysis, benzothiazole, indole, thiolation, $\mathrm{C}-\mathrm{H}$ functionalization

The formation of carbon-sulfur bonds is an important reaction in synthetic chemistry, as this motif is found in numerous natural products, pharmaceuticals, polymers, and semiconductors. ${ }^{1-8}$ The most common methods to achieve (C-S) bond formation have utilized transition-metal thiol cross-couplings: ${ }^{9-11}$ however, these methods typically involve harsh reaction conditions, high temperatures, and require pre-functionalization of the substrate. It would be more desirable to directly functionalize the $\mathrm{C}-\mathrm{H}$ bond without any intermediate transformation. Direct $\mathrm{C}-\mathrm{H}$ thiolation has been previously achieved through electrophilic aromatic substitution $\left(\mathrm{S}_{\mathrm{E}} \mathrm{Ar}\right)$ utilizing activated sulfenyl sources such as sulfenyl halides or $N$-thiosuccinimides. ${ }^{12-16}$ These reactions are limited primarily to electron-rich aromatics and heterocycles such as substituted indoles. We have recently reported methodologies that function via a Lewis base/Brønsted acid dual catalytic system that allow for the
C-H sulfenylation of diverse arenes. ${ }^{17,18}$ One drawback to this approach is that the formation of activated sulfenyl sources is often cumbersome; thus, methods that could activate readily available thiols in situ would represent a welcome advancement.

Over the past decade, radical chemistry, specifically photoredox catalysis and electrochemistry, has risen as a popular and powerful tool for $\mathrm{C}-\mathrm{H}$ functionalization. ${ }^{19-22}$

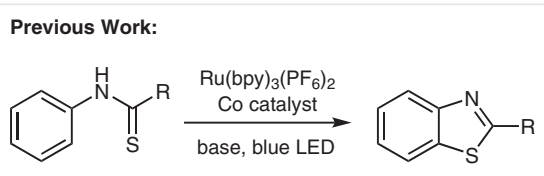

Lei, 2015


Scheme 1 Previous photocatalytic and electrochemical methodologies for $\mathrm{C}-\mathrm{H}$ thiolation of thioamides to benzothiazoles and various electron-rich heterocycles 
The radical species acts as a highly reactive intermediate, which enables synthetic transformations which normally cannot be assessed under reaction conditions involving polar pathways. ${ }^{23}$

In the past five years, there have been multiple accounts of $\mathrm{C}-\mathrm{H}$ thiolation employing the use of photoredox catalysis (Scheme 1). In 2015, Lei showed that benzothiazoles can be synthesized using a $\mathrm{Ru}(\mathrm{bpy})_{3}\left(\mathrm{PF}_{6}\right)_{2} / \mathrm{Co}$ dual catalytic system. ${ }^{24}$ Similarly, Xu reported a similar benzothiazole transformation from thioamides using a TEMPO-catalyzed electrochemical C-H thiolation. ${ }^{25}$ Alternatively, Barman and Fan both independently reported the use of Rose bengal and thiophenol for the sulfenylation of 3-substituted indoles and imidazopyridines, respectively. ${ }^{26,27}$ Recently, König and Rehbein showed that electron-rich arenes (such as trimethoxybenzenes) could react with diaryl and dialkyl sulfides with an iridium photocatalyst and a persulfate salt to provide arylthiols. ${ }^{28}$ Herein, we report an oxidative photocatalytic thiolation to synthesize benzothiazoles through an intramolecular synthesis from thioamides, as well as the intermolecular sulfenylation of substituted indoles (Scheme 2).

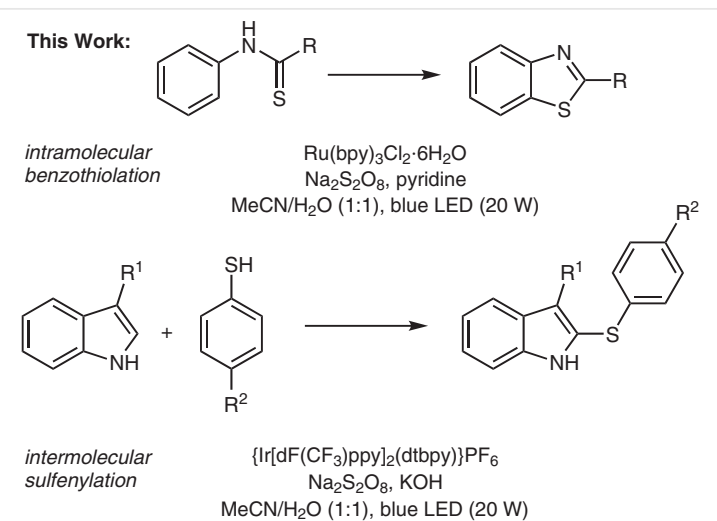

Scheme 2 Synthesis of benzothiazoles and sulfenylated indoles from oxidative photocatalytic conditions

Notably, mechanistic studies via cyclic voltammetry and density functional theory calculations suggest that even though both reactions use similar conditions, they proceed with markedly different roles for the sulfur, with an electrophilic sulfur radical in the benzothiazole formation, and a nucleophilic sulfur radical in the indole sulfenylation.

While studying whether the Lewis basic thioamide in 1a could act as a directing group for ortho- chlorination via $\mathrm{S}_{\mathrm{E}} \mathrm{Ar}$ using Hu's photocatalytic chlorination conditions ${ }^{29}$ we observed a significant amount of benzothiazole $\mathbf{1 b}$ (Table 1 , entry 1). Interestingly, removal of the sodium chloride provided a small increase in conversion of $\mathbf{1 a}$ into $\mathbf{1 b}$, suggesting this chemistry occurred via a substrate oxidative mechanism rather than sulfur activation through the halogen source (Table 1 , entry 2). Removal of both the $\mathrm{Ru}(\mathrm{bpy}){ }_{3} \mathrm{Cl}_{2}$ (Table 1 , entry 3 ) and sodium persulfate (Table 1 , entry 4 ) resulted in a significant decrease in conversion; however, there is a still a small benzothiazole background reaction in the presence of persulfate. We then continued our optimization with an evaluation of other common photocatalysts. Because we utilized a $390 \mathrm{~nm}$ LED blue light source, we hypothesized that $\mathrm{Ru}(\text { phen })_{3} \mathrm{Cl}_{2}\left(\mathrm{I}_{\max }=422 \mathrm{~nm}\right)$ would be in a higher absorbance range relative to $\mathrm{Ru}$ (bpy) ${ }_{3} \mathrm{Cl}_{2}\left(\mathrm{I}_{\max }=452\right.$ $\mathrm{nm}$ ). However, conversion of the benzothiazole was low at only $15 \%$ (Table 1 , entry 5 ). Switching from a transition metal to an organic photocatalyst 4CzIPN also provided no improvement in conversion (Table 1 , entry 6), possibly due to the reaction being performed in a biphasic solvent system. Surprisingly, $\left\{\operatorname{Ir}\left[\mathrm{dF}\left(\mathrm{CF}_{3}\right) \mathrm{ppy}\right]_{2}(\mathrm{dtbpy})\right\} \mathrm{PF}_{6}$, which has a higher oxidizing potential in its excited state $\left[\left(\operatorname{Ir}(\mathrm{III})^{*} / \mathrm{Ir}(\mathrm{II})=1.21 \mathrm{~V}\right.\right.$ vs $\left.\mathrm{SCE}\right]$ relative to $\mathrm{Ru}(\mathrm{bpy})_{3} \mathrm{Cl}_{2}$ $\left[\mathrm{Ru}(\mathrm{II})^{*} / \mathrm{Ru}(\mathrm{I})=0.77 \mathrm{~V}\right.$ vs SCE$]$ and would be expected to oxidize 1a more effectively, proved markedly worse than the ruthenium catalyst (Table 1, entry 7). Mechanistically, this implies that while the photocatalyst has a significant effect on the overall conversion of the reaction, its excited state does not directly oxidize the thioamide but rather likely activates the persulfate as a better oxidizing agent (see proposed mechanism). Testing solvent conditions, we observed a decrease in conversion when switching to a more organic composition of $\mathrm{MeCN} / \mathrm{H}_{2} \mathrm{O}$ (9:1), suggesting aqueous media is necessary to help solubilize the persulfate salt (Table 1 , entry 8). To see if circumventing persulfate activation was a possibility, we added excess amount of sodium persulfate (Table 1, entries 9 and 10); however, we only obtained the acetanilide side product, which is a common degradation product for thioamides under oxidative conditions. Finally, we observed that benzothiazole conversion could be improved markedly (up to 79\%) by the addition of two equivalents of pyridine as a base.

We decided to evaluate our conditions from Table 1, entry 11 across a variety of substituted thioamide derivatives (Scheme 3). To confirm our initial hypothesis, we tested the substrates in the absence and presence of pyridine and obtained isolated yields of the benzothiazoles. Varying the electronics at the aryl ring $\mathrm{R}^{1}$ (2a-5a) provided minor decreases in yield relative to the unsubstituted 1a (isolating between 49-63\% yield for $\mathbf{2 b - 5 b}$ ). Notably, we observed no effect when adding pyridine for naphthyl-based substrate 6a (54\% with no pyridine, 55\% with pyridine for $\mathbf{6 b}$ ) and substrate $\mathbf{7 a}$ (32\% without, $34 \%$ with pyridine for $\mathbf{7 b}$ ). This lack of pyridine effect held for other substrates that possessed these aryl groups 9a (43\% no pyridine, 38\% with pyridine for $\mathbf{9 b}$ ), and 15a (31\% no pyridine, 30\% with pyridine for 15b). Replacing the thioamide tert-butyl group 1a with a phenyl group in $\mathbf{8 a}$ resulted in a marked decrease in yield (79\% to $32 \%$ of $\mathbf{8 b}$ ); however other phenyl-containing thioamides resulted in decent yields (i.e., 10a resulted in 68\% yield 10b). Finally, when we replaced the thioamide substitution with aliphatic groups other than tert-butyl (11a14a), we isolated the corresponding benzothiazoles in good 
Table 1 Optimization of Intramolecular Benzothiazole Synthesis of 2,2-Dimethyl-N-phenylpropanethioamide ${ }^{\mathrm{a}}$

\begin{tabular}{|c|c|c|c|c|c|}
\hline Entry & Catalyst & Oxidant (equiv) & Additive (equiv) & Solvent & Conversion $(\%)^{\mathrm{b}}$ \\
\hline 1 & $\mathrm{Ru}(\text { bpy })_{3} \mathrm{Cl}_{2}$ & $\mathrm{Na}_{2} \mathrm{~S}_{2} \mathrm{O}_{8}(2)$ & $\mathrm{NaCl}(3)$ & $\mathrm{MeCN} / \mathrm{H}_{2} \mathrm{O}(1: 1)$ & 52 \\
\hline 2 & $\mathrm{Ru}(\mathrm{bpy})_{3} \mathrm{Cl}_{2}$ & $\mathrm{Na}_{2} \mathrm{~S}_{2} \mathrm{O}_{8}(2)$ & none & $\mathrm{MeCN} / \mathrm{H}_{2} \mathrm{O}(1: 1)$ & 57 \\
\hline 3 & $\mathrm{Ru}(\mathrm{bpy})_{3} \mathrm{Cl}_{2}$ & none & none & $\mathrm{MeCN} / \mathrm{H}_{2} \mathrm{O}(1: 1)$ & 0 \\
\hline 4 & none & $\mathrm{Na}_{2} \mathrm{~S}_{2} \mathrm{O}_{8}(2)$ & none & $\mathrm{MeCN} / \mathrm{H}_{2} \mathrm{O}(1: 1)$ & 5 \\
\hline 5 & $\mathrm{Ru}(\text { phen })_{3} \mathrm{Cl}_{2}$ & $\mathrm{Na}_{2} \mathrm{~S}_{2} \mathrm{O}_{8}(2)$ & none & $\mathrm{MeCN} / \mathrm{H}_{2} \mathrm{O}(1: 1)$ & 15 \\
\hline 6 & $4 C Z I P N$ & $\mathrm{Na}_{2} \mathrm{~S}_{2} \mathrm{O}_{8}(2)$ & none & $\mathrm{MeCN} / \mathrm{H}_{2} \mathrm{O}(1: 1)$ & 30 \\
\hline 7 & $\left\{\operatorname{Ir}\left[\mathrm{dF}\left(\mathrm{CF}_{3}\right) \mathrm{ppy}\right]_{2}(\mathrm{dtbpy})\right\} \mathrm{PF}_{6}$ & $\mathrm{Na}_{2} \mathrm{~S}_{2} \mathrm{O}_{8}(2)$ & none & $\mathrm{MeCN} / \mathrm{H}_{2} \mathrm{O}(1: 1)$ & 20 \\
\hline 8 & $\mathrm{Ru}(\mathrm{bpy})_{3} \mathrm{Cl}_{2}$ & $\mathrm{Na}_{2} \mathrm{~S}_{2} \mathrm{O}_{8}(2)$ & none & $\mathrm{MeCN} / \mathrm{H}_{2} \mathrm{O}(9: 1)$ & 34 \\
\hline 9 & $\mathrm{Ru}(\mathrm{bpy})_{3} \mathrm{Cl}_{2}$ & $\mathrm{Na}_{2} \mathrm{~S}_{2} \mathrm{O}_{8}(5)$ & none & $\mathrm{MeCN} / \mathrm{H}_{2} \mathrm{O}(1: 1)$ & 0 (1c obtained) \\
\hline 10 & $\mathrm{Ru}(\mathrm{bpy})_{3} \mathrm{Cl}_{2}$ & $\mathrm{Na}_{2} \mathrm{~S}_{2} \mathrm{O}_{8}(10)$ & none & $\mathrm{MeCN} / \mathrm{H}_{2} \mathrm{O}(1: 1)$ & 0 (1c obtained) \\
\hline 11 & $\mathrm{Ru}(\mathrm{bpy}){ }_{3} \mathrm{Cl}_{2}$ & $\mathrm{Na}_{2} \mathrm{~S}_{2} \mathrm{O}_{8}(2)$ & pyridine (2) & $\mathrm{MeCN} / \mathrm{H}_{2} \mathrm{O}(1: 1)$ & 79 \\
\hline
\end{tabular}

aReactions were performed on a. $130 \mathrm{mmol}$ scale (approximately $25 \mathrm{mg}$ ) with $5 \mathrm{~mol} \%$ photocatalyst loading in $1 \mathrm{~mL}$ of solvent mixture of MeCN/ $\mathrm{H}_{2} \mathrm{O}$.

${ }^{\mathrm{b} C}$ Conversions were measured by NMR integrated spectra; the results are reported as an average of two trials. See Supporting Information for the details.

yield (55-73\% 11b-14b). Surprisingly, when the thioamide substitution was a methyl (16a) we only isolated the corresponding amide. Alternatively, when we evaluated trifluoromethyl containing $\mathbf{1 7 a}$, we observed no reaction of any kind, perhaps due to the thioamide being significantly more electron poor and possessing a higher redox potential, or a lower innate nucleophilicity.

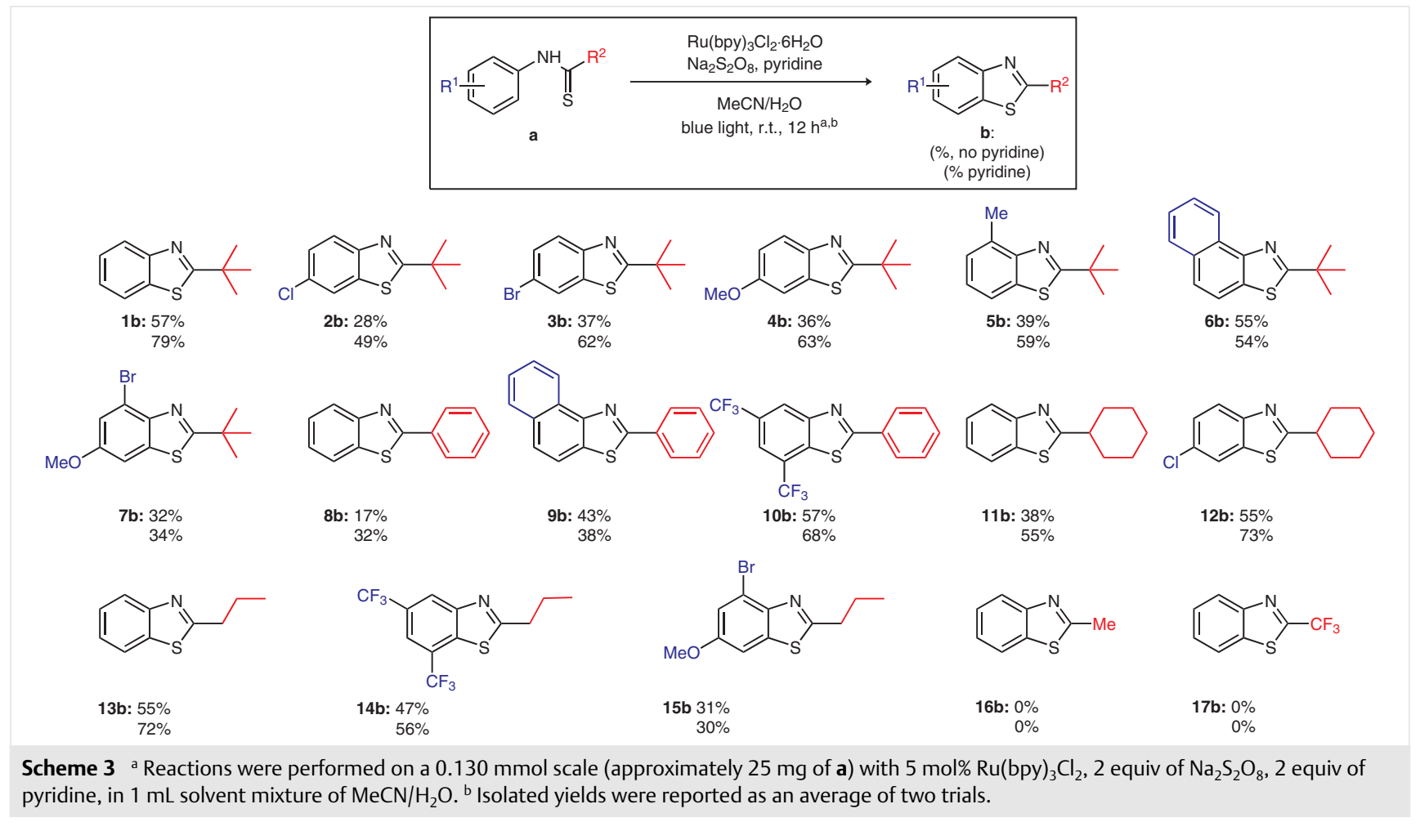



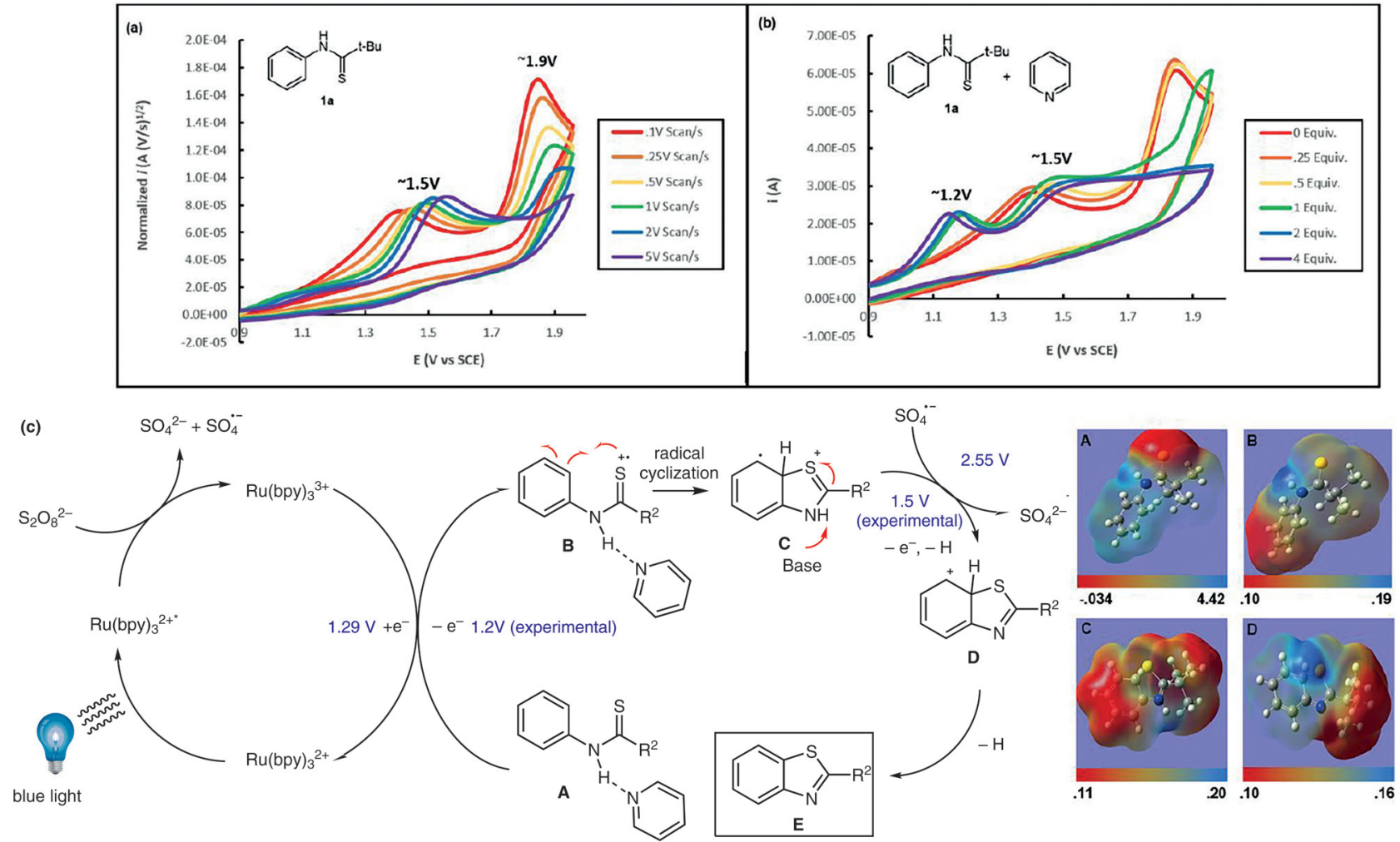

Scheme 4 Cyclic voltammetry (CV) measurements of substrate 1 a with variation in potential scan rate (a) and with pyridine additive (b). Both processes show two oxidation peaks in an irreversible process. Increasing the scan rate shows disappearance of the second oxidation peak, implying a chemical reaction step between the first and second oxidation towards product formation. Titration of pyridine shows a lowering of both oxidation potentials. CV experiments were run vs Ag wire reference electrode, a glassy carbon working electrode, and a platinum counter electrode, followed by standard conversions to saturated calomel electrode (SCE). (c) A proposed mechanism for intramolecular benzothialation is shown, with electron-density maps derived from density functional theory (DFT) structure optimizations. The key experiments suggest an initial oxidation at the sulfur to form the thiyl radical cation, which then undergoes intramolecular cyclization. Coordination of the pyridine additive to the substrate lowers the first half-wave oxidation due to coordination with the $\mathrm{N}-\mathrm{H}$ thioamide bond, providing a more favorable single-electron-transfer process.

To explain the subsequent transformation, we propose the following mechanism (Scheme 4), which is supported by several key experiments. Due to the increase in yield upon addition of pyridine, we believe there is a Lewis base effect wherein the pyridine coordinates to the $\mathrm{N}-\mathrm{H}$ thioamide bond, providing extra stability to the radical cation that forms upon initial oxidation. This hypothesis is substantiated through cyclic voltammetry experiments on substrate $\mathbf{A}$. In pure acetonitrile without the presence of additive base, we observed two half-wave oxidation potentials at $1.5 \mathrm{~V}$ and $1.9 \mathrm{~V}$ vs SCE, meaning both values are out of the range of the $\mathrm{Ru}(\mathrm{bpy})_{3} \mathrm{Cl}_{2}$ reduction potential in its excited state $\left[\mathrm{Ru}(\mathrm{II})^{*} / \mathrm{Ru}(\mathrm{I})=0.77 \mathrm{~V}\right.$ vs SCE]. Upon titration of pyridine, we noticed a distinct shift in the two oxidation potentials to $1.2 \mathrm{~V}$ and $1.5 \mathrm{~V}$ vs SCE. Interestingly, the first oxidation potential of $\mathbf{A}$ with pyridine is now within the range of the ground-state reduction potential of $\mathrm{Ru}(\mathrm{bpy})_{3} \mathrm{Cl}_{2}$ $[\mathrm{Ru}(\mathrm{III}) / \mathrm{Ru}(\mathrm{II})=1.29 \mathrm{~V}$ vs SCE$]$. This suggests that, in its excited state, the photocatalyst reduces persulfate to the $\mathrm{SO}_{4}{ }^{2-}$ anion and the $\mathrm{SO}_{4}{ }^{-}$anion radical, followed by the resultant
$\mathrm{Ru}^{3+}$ complex oxidizing the thioamide substrate to radical cation B. Additionally, we utilized density functional theory (DFT) calculations to predict the electron-density maps for several thioamide intermediates and consequently predict the most favorable sites for oxidation. In the first map, we see a large concentration of electron density at the sulfur relative to the rest of the molecule $\mathbf{A}$, implying it is the most favorable site for initial oxidation; this pathway is also supported by recently reported work from Nicewicz on allylic thioamides. ${ }^{32,33}$

At this point, B will likely undergo radical cyclization to C. This is supported by CV scan-rate experiment; as we sweep from $0.1 \mathrm{~V} / \mathrm{s}$ to $5 \mathrm{~V} / \mathrm{s}$, the second half-wave oxidation peak begins to diminish and completely disappears at the highest scan rate. One explanation for this observation is there is a new intermediate reaction between the first and second oxidation (i.e., thioamide cyclization) and that faster voltage sweeps can kinetically outpace the reaction, thereby hindering subsequent oxidation. Additionally, the predicted electron map of B suggests that the sulfur is now 
more electron deficient compared to the aryl ring; thus, it is likely that the cyclization will occur via the arene acting as a nucleophile and the sulfur acting as an electrophilic radical. Due to the comparable yields of electron-deficient thioamides without the presence of pyridine (i.e., 10a), we believe that the additive is beneficial towards initial oxidation but not necessary as persulfate can also promote formation of the thiyl radical cation; it is the subsequent radical cyclization which drives the reaction favorably towards the benzothiazole product. Upon cyclization, the electron-density map shows a more electron-rich intermediate which should be easily oxidized by the persulfate radical anion to give Wheland arenium ion $\mathbf{D}$, which will rapidly undergo aromatization to the final product $\mathbf{E}$.

We also explored whether our methodology for intramolecular $\mathrm{C}-\mathrm{H}$ thiolation could be applied to other arenes for intermolecular functionalization, specifically the sulfenylation of electron-rich heterocycles such as indoles. Our initial experiment utilized our optimized conditions for benzothiazole synthesis without pyridine, using 18a melatonin as the substrate and 4-methyl thiophenol as the sulfenylating reagent, and obtained $29 \%$ yield of $\mathbf{1 8 b}$ (Table 2 , entry 1 ). Upon addition of pyridine (Table 2, entries 2 and 3), we observed a similar trend as the yields increased to $40 \%$. Just like the previous reaction, removal of the photocatalyst diminishes the yield significantly to $8 \%$ (Table 2 , entry 4 ), however, there is still a background reaction from just persulfate exclusively. Interestingly, reintroduction of the photocatalyst but cutting the persulfate equivalent in half reduced the overall yield to $5 \%$ (Table 2 , entry 5 ). As expected, complete removal of persulfate provides no reaction (Table 2 , entry 6).

Similar trends also hold for changing the ratio of solvents, as we see almost no variation going from 1:1 to $9: 1$ $\mathrm{MeCN} / \mathrm{H}_{2} \mathrm{O}$, and a lowering of $15 \%$ yield switching to completely acetonitrile (Table 2 , entries 7 and 8 ). After evaluat-

Table 2 Optimization of Intermolecular Sulfenylation of Melatonin with 4-Methyl Thiophenol (18a) ${ }^{\mathrm{a}}$

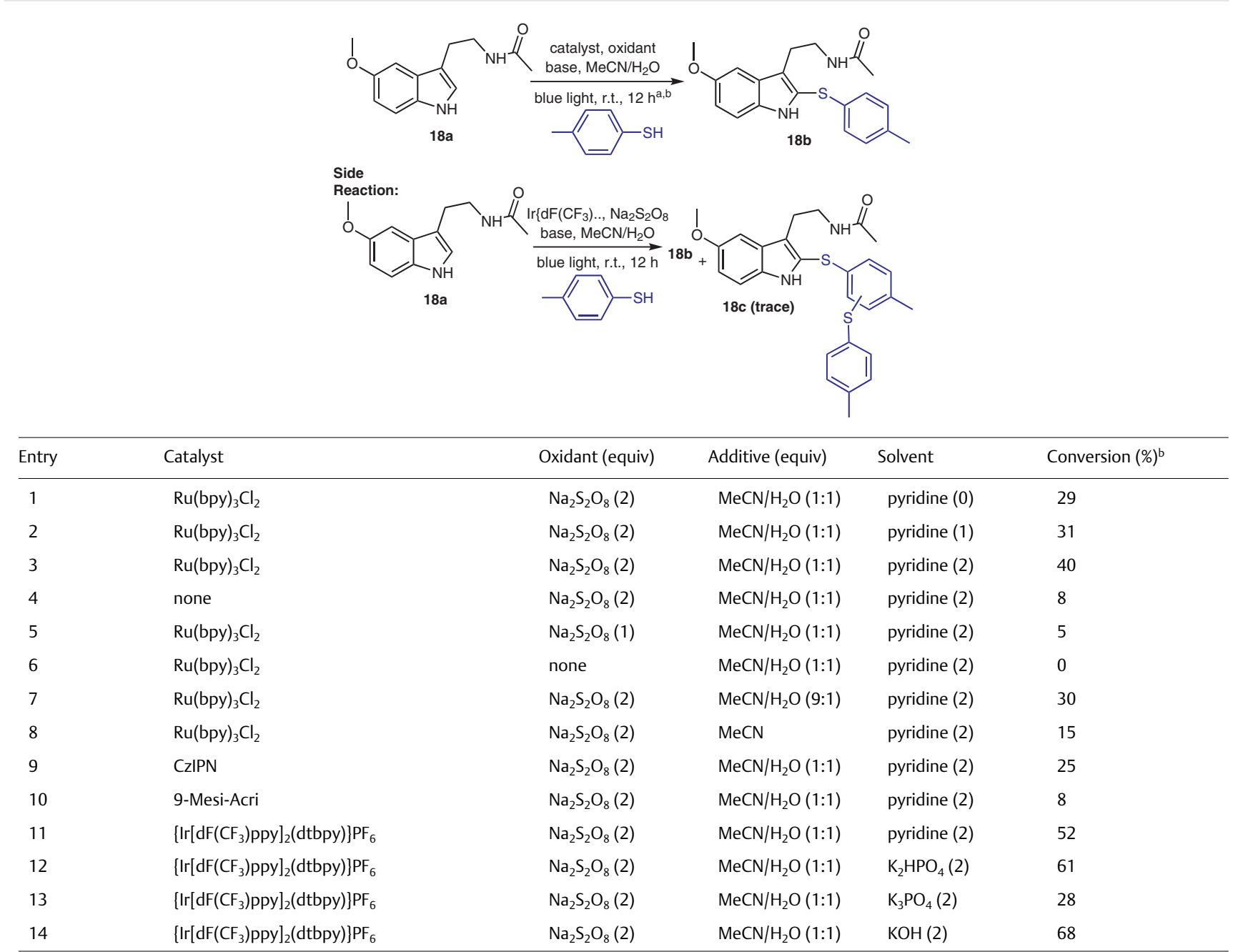

aReactions were performed on a $0.130 \mathrm{mmol}$ scale (approximately $25 \mathrm{mg}$ 18a) with $5 \mathrm{~mol} \%$ photocatalyst loading in $1 \mathrm{~mL}$ of solvent mixture of MeCN/ $\mathrm{H}_{2} \mathrm{O}$. ${ }^{b}$ Conversions were measured by NMR integrated spectra; the results are reported as an average of two trials. See Supporting Information for more details. 
ing a number of photocatalysts (Table 2, entries 9-11), we observed that $\left\{\operatorname{Ir}\left[\mathrm{dF}\left(\mathrm{CF}_{3}\right) \mathrm{ppy}\right]_{2}(\mathrm{dtbpy})\right\} \mathrm{PF}_{6}$ gave a much higher yield at $52 \%$ compared with $\mathrm{Ru}(\mathrm{bpy})_{3} \mathrm{Cl}_{2}$. Finally, variation of the base to potassium hydroxide (Table 2 , entries 12-14) provided an increase of yield to $68 \%$. Interestingly, we noticed a trace amount of a disulfenylated side product $18 \mathrm{c}$ when the iridium photocatalyst is used, suggesting that at some point the thiophenol reagent (or product sulfide) is oxidized and reacts with a second equivalent of thiophenol.

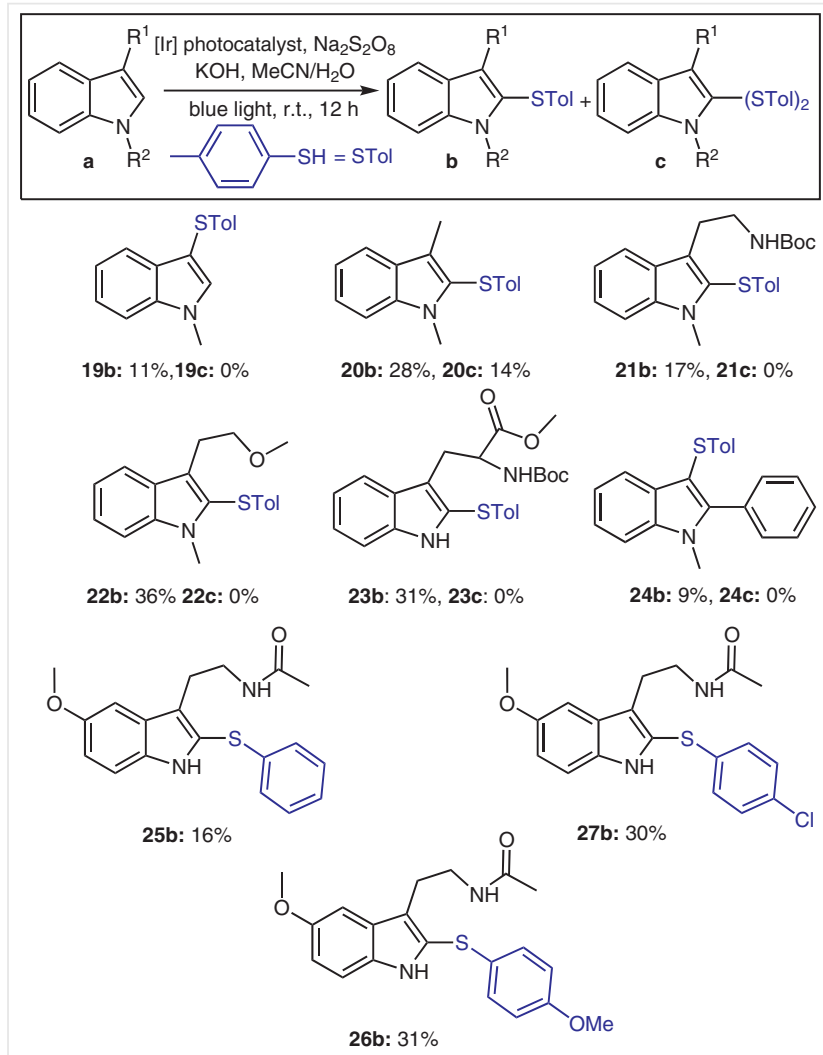

Scheme 5 Sulfenylation of various substituted indoles. Both the monoand disulfenylated product were obtained on a substrate-dependent basis, with most substrates providing exclusively the monosulfenylated product. Reactions were performed on a $130 \mathrm{mmol}$ scale (approximately 25 $\mathrm{mg}$ ) with $2.5 \mathrm{~mol} \%$ photocatalyst in $1 \mathrm{~mL}$ of solvent mixture of $\mathrm{MeCN} / \mathrm{H}_{2} \mathrm{O}$. Isolated yields are reported as an average of two trials. See Supporting Information for more details.

With our optimized conditions, we evaluated a number of substituted indoles and report the isolated yields of both the mono- and disulfenylated product, with a majority of substrates providing exclusively the monosulfenylated product in 9-36\% yield (Scheme 5, 19-24). Similar to melatonin, $N$-methyl 3-methylindole (20a) also gave a mixture of monosulfenylated 20b and disulfenylated 20c (28\% and $14 \%$, respectively) Additionally, we tested a number of benzenethiol reagents (25a-27a) and varied the electronics off the aryl ring; this gave attenuated yields ranging from 16-
31\% yield (25b-27b). While these yields are moderate compared to other conditions (both via traditional $S_{E} A r$, and photocatalysis), we find it notable that this sulfenylation worked on biologically relevant scaffolds such as melatonin and tryptophan. We also found this transformation mechanistically interesting as the conditions were nearly identical to those of the benzothiazole synthesis and performed a series of mechanistic studies.

We first determined the experimental redox potentials of melatonin and 4-methylbenzenethiol sulfenylating reagent. We observed that the melatonin 18a has a first halfwave oxidation potential of $1.10 \mathrm{~V}$ vs SCE while the latter has a higher half-wave oxidation potential of $1.49 \mathrm{~V}$ vs SCE (see Supporting Information). Consequently, in its excited triplet state, the $\left\{\operatorname{Ir}\left[\mathrm{dF}\left(\mathrm{CF}_{3}\right) \mathrm{ppy}\right]_{2}(\mathrm{dtbpy})\right\} \mathrm{PF}_{6}$ photocatalyst would be out of the potential range for oxidation of 4-methylbenzenethiol, and initial oxidation likely occurs at melatonin to form the cation radical F. Stern-Volmer quenching studies between the iridium photocatalyst, melatonin, and 4-methylbenzenethiol supports this hypothesis as melatonin $\left(\mathrm{K}_{\mathrm{sv}}=4.2 \mathrm{M}^{-1} \mathrm{~L}\right)$ is quenched at a much higher rate than the thiophenol $\left(\mathrm{K}_{\mathrm{sV}}=0.1 \mathrm{M}^{-1} \mathrm{~L}\right)$ (see Scheme 6 and Supporting Information). Additionally, we ran the photocatalytic reaction in the absence of indole, observing a significant amount of the disulfide byproduct, which is known to undergo homolytic cleavage under UV light to form the thiyl radical. ${ }^{35}$ To test whether the disulfide was an intermediate, we evaluated the reaction using phenyl disulfide as the sulfur source, observing comparable yields to that of thiophenol. Stern-Volmer quenching of the photocatalyst with 4-methyldiphenyl disulfide provided a slight increase $\left(\mathrm{K}_{\mathrm{sv}}=0.6 \mathrm{M}^{-1} \mathrm{~L}\right)$ relative to the thiophenol but still significantly less than melatonin. To confirm out findings, we ran a sulfenylation cross experiment using both 4-methylbenzenethiol and phenyl sulfide, observing the methylated indole as the main product via mass spectrometry (see Supporting Information). Based on these experiments, two plausible simultaneous mechanisms can occur. Once indole cation radical $\mathbf{F}$ is formed, deprotonated thiophenol can nucleophilically attack $\mathbf{F}$ to form radical intermediate $\mathbf{G}$, which will be oxidized by persulfate and aromatize to form the sulfenylated product 18b (Scheme 6, pathway 1). Alternatively, under photocatalytic conditions, thiophenol can be converted into disulfide which can homolytically disassociate to form the thiyl radical. The radical can undergo radical coupling with $\mathbf{F}$ to form Wheland intermediate $\mathbf{H}$, followed by aromatization to form product $\mathbf{1 8 b}$. Both pathways can occur simultaneously; however, we believe that the nucleophilic pathway is predominant as shown by Stern-Volmer quenching studies and sulfenylation cross experiment.

In conclusion we have developed an operationally simple and economical method to synthesize benzothiazoles via photocatalytic $\mathrm{C}-\mathrm{H}$ thiolation and have extended these conditions to indole sulfenylation. ${ }^{36}$ We performed mecha- 

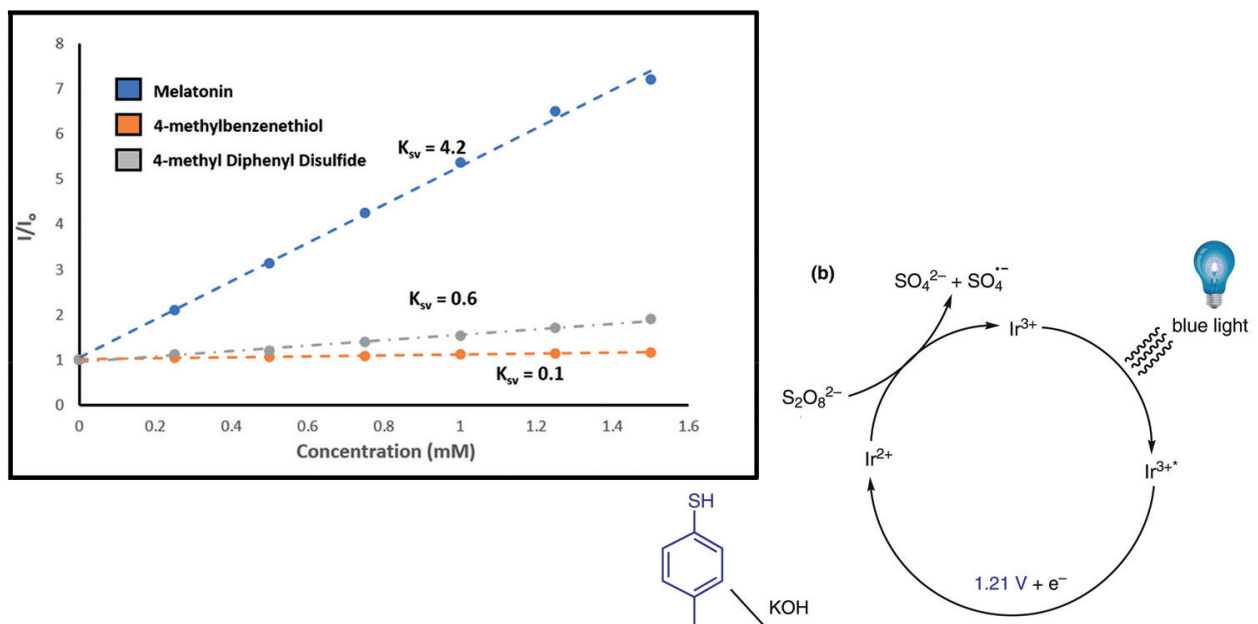
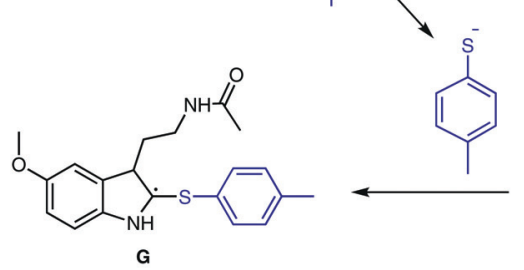

18a, $\mathrm{Na}_{2} \mathrm{~S}_{2} \mathrm{O}_{8}, \mathrm{KOH}$<smiles>COc1ccc2c(c1)C(CCNC(C)=O)[CH+]N[C@H]2O</smiles>

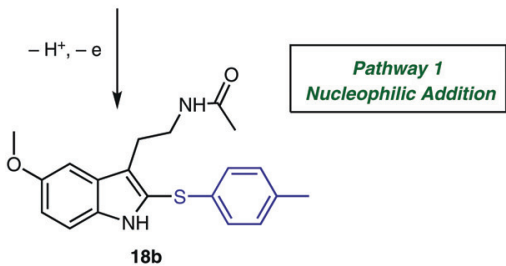

Scheme 6 (a) Stern-Volmer quenching plots of the $\left[\operatorname{Ir}\left[\mathrm{dF}\left(\mathrm{CF}_{3}\right) \mathrm{ppy}\right]_{2}(\mathrm{dtbpy})\right] \mathrm{PF}_{6}$ with melatonin, 4-methylbenzenethiol, and 4-methyl diphenyl disulfide, shown with $\mathrm{K}_{\mathrm{sv}}$ values. (b) Proposed mechanism pathways for the intermolecular sulfenylation of indoles. Deprotonated thiophenol can nucleophilically attack the oxidized indole (pathway 1 ) or homolytically couple to the radical indole to obtain the substituted product.

nistic studies that suggest that the sulfur displays divergent activities (nucleophilic or electrophilic radical) in the two reactions.

\section{Funding Information}

This work was supported by the National Science Foundation (Grant No. Che-1664565).

\section{Acknowledgement}

A.N.D. is supported by the SDSU Graduate Student Fellowship. We would like to thank Professor Yong Yan (SDSU) and Dr. Xiaolin Zhu (SDSU) for insightful discussion regarding the photocatalytic mechanisms and assistance with Stern-Volmer studies, and Dr. Bennett Addison (SDSU) for support with NMR instrumentation.

\section{Supporting Information}

Supporting information for this article is available online at https://doi.org/10.1055/s-0039-1690107.

\section{References and Notes}

(1) Dunbar, K. L.; Scharf, D. H.; Litomska, A.; Hertweck, C. Chem. Rev. 2017, 117, 5521.

(2) Johannesson, P.; Lindeberg, G.; Johansson, A.; Nikiforovich, G. V.; Gogoll, A.; Synnergren, B.; Gre, M. L.; Nyberg, F.; Karlen, A.; Hallberg, A. J. Med. Chem. 2002, 45, 1767.

(3) Kazemi, M.; Shiri, L.; Kohzadi, H.; Kazemi, M.; Shiri, L.; Kohzadi, H. Phosphorus, Sulfur, Silicon Relat. Elem. 2015, 190, 978.

(4) Marcantoni, E.; Massaccesi, M.; Petrini, M.; Bartoli, G.; Bellucci, M. C.; Bosco, M.; Sambri, L. J. Org. Chem. 2000, 65, 4553.

(5) Vazquez-Prieto, M. A.; Miatello, R. M. Mol. Aspects Med. 2010, 31, 540.

(6) Vouillamoz, J.; Entenza, M.; Hohl, P.; Moreillon, P. Antimicrob Agents Chemother 2004, 48, 4322.

(7) Takimiya, K.; Osaka, I.; Mori, T.; Nakano, M. Acc. Chem. Res. 2014, 47, 1493. 
(8) Gill, R.; Rawal, R.; Bariwal, J. Arch. Pharm. Chem. Life Sci. 2015, $348,155$.

(9) Lee, C.; Liu, Y.; Badsara, S. S. Chem. Asian J. 2014, 9, 706.

(10) Beletskaya, I. P.; Ananikov, V. P. Chem. Rev. 2011, 111, 1596.

(11) Vásquez-Céspedes, S.; Ferry, A.; Candish, L.; Glorius, F. Angew. Chem. Int. Ed. 2015, 54, 5772.

(12) Stavber, S. Molecules 2011, 16, 6432.

(13) Schlosser, K. M.; Krasutsky, A. P.; Hamilton, H. W.; Reed, J. E.; Sexton, K. Org. Lett. 2004, 6, 819.

(14) Tudge, M.; Tamiya, M.; Savarin, C.; Humphrey, G. R. Org. Lett. 2006, 8, 565.

(15) Gillis, M.; Greene, L.; Thompson, A. Synlett 2009, 112.

(16) Matsugi, M.; Murata, K.; Nambu, H.; Kita, Y. Tetrahedron 2001, 42, 1077.

(17) Nalbandian, C. J.; Brown, Z. E.; Alvarez, E.; Gustafson, J. L. Org. Lett. 2018, 20, 3211.

(18) Nalbandian, C. J.; Miller, E. M.; Toenjes, S. T.; Gustafson, J. L. Chem. Commun. 2017, 53, 1494.

(19) Prier, C. K.; Rankic, D. A.; Macmillan, D. W. C. Chem. Rev. 2013, $113,5322$.

(20) Romero, N. A.; Nicewicz, D. A. Chem. Rev. 2016, 116, 10075.

(21) Wang, C.; Dixneuf, P.; Soule, J.-F. Chem. Rev. 2018, 118, 7532.

(22) Shaw, M. H.; Twilton, J.; Macmillan, D. W. C. J. Org. Chem. 2016, $81,6898$.

(23) Smith, J. M.; Harwood, S. J.; Baran, P. S. Acc. Chem. Res. 2018, 51, 1807.

(24) Zhang, G.; Liu, C.; Yi, H.; Meng, Q.; Bian, C.; Chen, H.; Jian, J.; Wu, L.; Lei, A. J. Am. Chem. Soc. 2015, 137, 9273.

(25) Qian, X.; Li, S.; Song, J.; Xu, H. ACS Catal. 2017, 7, 2730.

(26) Rahaman, R.; Das, S.; Barman, P. Green Chem. 2018, 20, 141.

(27) Guo, W.; Tan, W.; Zhao, M.; Tao, K.; Zheng, L.; Wu, Y.; Chen, D.; Fan, X. RSC Adv. 2017, 7, 37739.

(28) Das, A.; Maity, M.; Malcherek, S.; König, B.; Rehbein, J. Beilstein J. Org. Chem. 2018, 14, 2520.

(29) Zhang, L.; Hu, X. Chem. Sci. 2017, 8, 7009.

(30) Rountree, K. J.; Mccarthy, B. D.; Rountree, E. S.; Eisenhart, T. T.; Dempsey, J. L. J. Chem. Educ. 2017, 95, 197.

(31) Hua, A. M.; Bidwell, S. L.; Baker, S. I.; Hratchian, H. P.; Baxter, R. D. ACS Catal. 2019, 9, 3322.

(32) Cruz, C. L.; Nicewicz, D. A. ACS Catal. 2019, 9, 3926.

(33) Morse, P. D.; Nicewicz, D. A. Chem. Sci. 2015, 6, 270.

(34) Mcmanus, J. B.; Nicewicz, D. A. J. Am. Chem. Soc. 2017, 139, 2880.

(35) Denes, F.; Pichowicz, M.; Povie, G.; Renaud, P. Chem. Rev. 2014, 114, 2587.

(36) General Procedure for Synthesis of Substituted Benzothiazoles

In a $10 \mathrm{~mL}$ scintillation vial, thioabenzamide (1.0 equiv),
$\mathrm{Ru}(\text { bpy })_{3} \mathrm{Cl}_{2}$ (5 mol\%), $\mathrm{Na}_{2} \mathrm{~S}_{2} \mathrm{O}_{8}$ (2.0 equiv), and pyridine (2.0 equiv) were added to a solution of $1: 1 \mathrm{MeCN} / \mathrm{H}_{2} \mathrm{O}(25 \mathrm{mg} / 1 \mathrm{~mL})$. The reaction was stirred under blue LEDs for $12 \mathrm{~h}$ at room temperature. The resulting solution was quenched with $\mathrm{H}_{2} \mathrm{O}$, extracted with EtOAc, dried over $\mathrm{Na}_{2} \mathrm{SO}_{4}$, and concentrated in vacuo. The product was purified via FCC and prep TLC with gradient from hexanes to 8:2 Hex/EtOAc.

General Procedure for the Synthesis of Sulfenylated Indoles In a $10 \mathrm{~mL}$ scintillation vial, substituted indole (1.0 equiv), $\left\{\operatorname{Ir}\left[\mathrm{dF}\left(\mathrm{CF}_{3}\right) \mathrm{ppy}\right]_{2}(\mathrm{dtbpy})\right\} \mathrm{PF}_{6}$ photocatalyst (1 mol\%), $\mathrm{Na}_{2} \mathrm{~S}_{2} \mathrm{O}_{8}$ (2.0 equiv), $\mathrm{KOH}$ (2.0 equiv), and thiophenol (1.2 equiv) were added to a solution of $1: 1 \mathrm{MeCN} / \mathrm{H}_{2} \mathrm{O}(25 \mathrm{mg} / 1 \mathrm{~mL})$. The reaction was left to stir under blue LEDs for $12 \mathrm{~h}$ at room temperature. The resulting solution was quenched with $\mathrm{H}_{2} \mathrm{O}$ and extracted with EtOAc, dried over $\mathrm{Na}_{2} \mathrm{SO}_{4}$, and concentrated in vacuo. The product was purified via FCC and prep TLC $(8: 2$ Hex/EtOAc). Melatonin substrates were purified via FCC with (2:8 Hex/EtOAc).

\section{2-(tert-Butyl)benzo[d]thiazole (1b)}

$57 \%$ with no pyridine, $79 \%$ with pyridine, off-white solid. ${ }^{1} \mathrm{H}$ $\operatorname{NMR}\left(500 \mathrm{MHz}, \mathrm{CDCl}_{3}\right): \delta=8.00(\mathrm{dt}, \mathrm{J}=8.2,0.9 \mathrm{~Hz}, 1 \mathrm{H}), 7.85$ (dd, J = 8.0, 0.45 Hz, $1 \mathrm{H}$ ), 7.44 (ddd, $\mathrm{J}=8.3,7.2,1.3 \mathrm{~Hz}, 1 \mathrm{H}$ ), 7.34 (ddd, J = 8.2, 7.2, $1.2 \mathrm{~Hz}, 1 \mathrm{H}$ ), $1.53(\mathrm{~s}, 9 \mathrm{H}$ ). The spectral data are in agreement with the reported literature. ${ }^{37}$ MS-APCI: $\mathrm{m} / \mathrm{z}$ calcd: $\mathrm{C}_{11} \mathrm{H}_{13} \mathrm{NS}[\mathrm{M}+\mathrm{H}]^{+}$192.3; found: 192.1.

2-(tert-Butyl)napthol[1,2-d]thiazole (6b)

$55 \%$ with no pyridine, $54 \%$ with pyridine, yellow-green solid. ${ }^{1} \mathrm{H}$ $\operatorname{NMR}\left(500 \mathrm{MHz}, \mathrm{CDCl}_{3}\right): \delta=8.82(\mathrm{dt}, \mathrm{J}=8.0,0.8 \mathrm{~Hz}, 1 \mathrm{H}), 7.93(\mathrm{~d}$, $\mathrm{J}=8.1 \mathrm{~Hz}, 1 \mathrm{H}), 7.87(\mathrm{~d}, \mathrm{~J}=8.7 \mathrm{~Hz}, 1 \mathrm{H}), 7.75(\mathrm{~d}, \mathrm{~J}=8.7 \mathrm{~Hz}, 1 \mathrm{H})$, 7.65 (ddd, $\mathrm{J}=8.2,6.9,1.3 \mathrm{~Hz}, 1 \mathrm{H}$ ), 7.55 (ddd, $\mathrm{J}=8.2,6.9,1.3 \mathrm{~Hz}$, $1 \mathrm{H}), 1.59$ (s, $9 \mathrm{H}) .{ }^{13} \mathrm{C}$ NMR $\left(101 \mathrm{~Hz}, \mathrm{CDCl}_{3}\right): \delta=180.7,149.2$, 131.8, 131.2, 128.6, 127.9, 126.6, 125.7, 125.0, 124.0, 119.0, 38.4, 31.0. MS-APCI: $\mathrm{m} / z$ calcd for $\mathrm{C}_{15} \mathrm{H}_{15} \mathrm{NS}[\mathrm{M}+\mathrm{H}]^{+}$: 242.4; found: 242.1 .

$\mathrm{N}$-\{2-[5-Methoxy-2-(p-tolylthio)-1H-indol-3- yl]ethyl\}acetamide (18b)

$68 \%$, tan solid. ${ }^{1} \mathrm{H}$ NMR $\left(400 \mathrm{MHz}, \mathrm{CDCl}_{3}\right): \delta=8.12(\mathrm{~s}, 1 \mathrm{H}), 7.22$ (d, 8.8 Hz, $1 \mathrm{H}), 7.02-7.06(\mathrm{~m}, 3 \mathrm{H}), 6.98(\mathrm{~d}, 8.3 \mathrm{~Hz}, 2 \mathrm{H}), 6.91$ $(\mathrm{dd}, \mathrm{J}=8.8,2.4 \mathrm{~Hz}, 1 \mathrm{H}), 5.50(\mathrm{~s}, 1 \mathrm{H}), 3.86(\mathrm{~s}, 3 \mathrm{H}), 3.52(\mathrm{q}, \mathrm{J}=6.4$ $\mathrm{Hz}, 2 \mathrm{H}), 3.05$ (t, J = 6.5 Hz, $2 \mathrm{H}), 2.27(\mathrm{~s}, 3 \mathrm{H}), 1.78(\mathrm{~s}, 3 \mathrm{H}) .{ }^{13} \mathrm{C}$ NMR $\left(126 \mathrm{~Hz}, \mathrm{CDCl}_{3}\right): \delta=170.28,154.36,136.17,133.22$, $132.07,130.04,128.13,127.00,123.50,119.64,114.32,111.93$, 100.32, 55.87, 40.01, 24.75, 23.13, 20.89. MS-APCI: $m / z$ calcd for $\mathrm{C}_{20} \mathrm{H}_{22} \mathrm{~N}_{2} \mathrm{O}_{2} \mathrm{~S}[\mathrm{M}+\mathrm{H}]^{+}: 355.5$; found: 355.5

(37) Zhang, G.; Liu, C.; Yi, H.; Meng, Q.; Bian, C.; Chen, H.; Jian, J. X.; Wu, L. Z.; Lei, A. J. Am. Chem. Soc. 2015, 137, 9273. 